\title{
Nerve Cell Deterioration Associated with Alzheimer's Disease
}

Yaping Tu

University of South Florida

\author{
Advisors: \\ Arcadii Grinshpan, Mathematics and Statistics \\ Andrei Chugunov, Fortis College: Medical Sciences \\ Problem Suggested By: Andrei Chugunov
}

Follow this and additional works at: https://digitalcommons.usf.edu/ujmm

Part of the Mathematics Commons

UJMM is an open access journal, free to authors and readers, and relies on your support:

Donate Now

\section{Recommended Citation}

Tu, Yaping (2010) "Nerve Cell Deterioration Associated with Alzheimer's Disease," Undergraduate Journal of Mathematical Modeling: One + Two: Vol. 3: Iss. 1, Article 17.

DOI: http://dx.doi.org/10.5038/2326-3652.3.1.29

Available at: https://digitalcommons.usf.edu/ujmm/vol3/iss1/29 


\title{
Nerve Cell Deterioration Associated with Alzheimer's Disease
}

\begin{abstract}
Alzheimer's disease is an extremely serious condition that is challenging to diagnose. We have used experimental data to compare the rate of decay of entorhinal cortex (EC) neurons in various stages of Alzheimer's. We observed that the rate of EC neuron decay in the patients without Alzheimer's is close to zero, linear in mild cases, and quadratic in severe cases. We believe that described estimates may help to diagnose the disease as well as its stage.
\end{abstract}

\section{Keywords}

Nerve Cell Deterioration, Alzheimer's Disease, Entorhinal Cortex

Creative Commons License

(c) (i) (2)

This work is licensed under a Creative Commons Attribution-Noncommercial-Share Alike 3.0 United States License.

\section{Erratum}

This article was previously called Article 29. 


\section{TABLE OF CONTENTS}

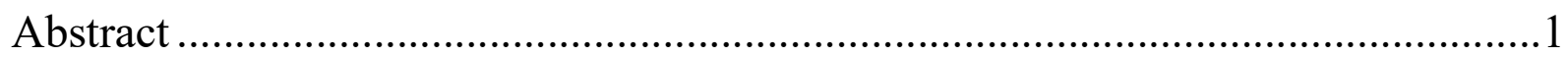

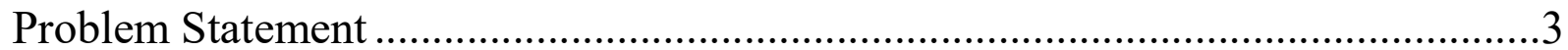

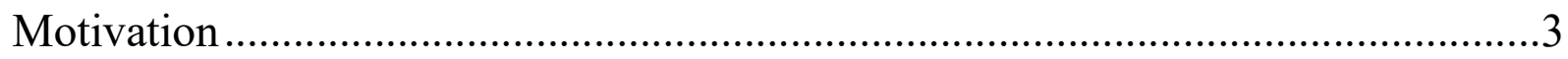

Mathematical Description and Solution Approach.............................................4

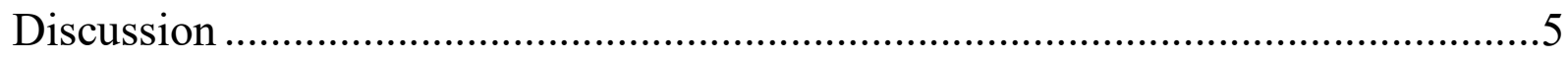

Conclusion and Recommendations ...........................................................6

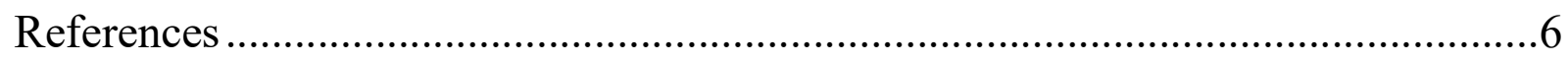

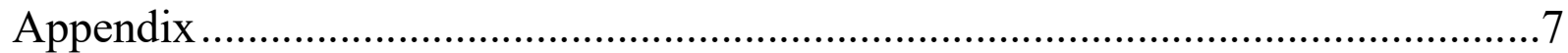




\section{PROBLEM STATEMENT}

Formulate the Trend of Nerve Cell Decrease in Alzheimer's Patients.

\section{MOTIVATION}

According to Barbara Hamann, the author of Disease: Identification, Prevention, and Control, $30 \%$ of people over the age of 85 suffer from Alzheimer's disease, making it the most common neurodegenerative disease. The author also states that a laboratory test has yet to be established to diagnose the disease, so an autopsy remains the only reliable way to confirm the Alzheimer's.

Currently, Alzheimer's disease treatments are prescribed to the patients only after ruling out other neurodegenerative diseases (Hamann, 402). Of course, this approach does not guarantee that the patient is being provided with the correct treatment. To explore more accurate ways of diagnosing Alzheimer's disease, we compare the quantity of entorhinal cortex (EC) neurons in the of Alzheimer patients to the quantity of EC neurons in subjects that don't have Alzheimer's in hopes to find a pattern in the rate of EC neuron decrease that could serve as a marker characteristic for the disease.

EC is located at the medial temporal lobe, carries on important functions supporting the hippocampal formation and the neocortex in regards to memory formation, learning, and higher order cortical processing ("Entorhinal Cortex."). The EC is the first known area to be affected by Alzheimer's disease. While neurofibrillary tangles and senile plaques are important signs of Alzheimer's disease onset, the occurrence of the two symptoms are also observed in healthy brains (Gomez-Isla, 4491). The number of neurons in the entrohinal cortex is known to show a 
significant decrease in Alzheimer's patients, while the number of neurons remains relatively constant throughout a normal human's lifespan (Sutherland, 438). The severity of Alzheimer's disease is determined by the Washington University Clinical Dementia Rating (CDR). A CDR of zero indicates the patient is healthy, a score of 0.5 shows the patient has very mild symptoms of the illness, a score of 1 indicates mild, a score of 2 indicates moderate, and a score of 3 indicates severe (Gomez-Isla, 4492).

\section{MATHEMATICAL DESCRIPTION AND SOLUTION APPROACH}

In this work we use data reporting the decrease in number of entorhinal cortex (EC) neurons of Alzheimer's patients and normal subjects (Gomez-Isla, 4492). The data describes quantity of EC neurons for subjects in three categories according to their CDR: the control group, patients suffering a mild form of Alzheimer's disease, and patients suffering from severe Alzheimer's disease (see Figure 4). We have calculated the following lines of best fit for each of the groups.

1. Control $y=-0.0013 x+7.0104$

2. Mild AD $y=-0.0261 x+7.2616$

3. Severe AD $y=-0.0156 x^{2}+2.3018 x-81.79$

For the first two categories, we have used the following equation to estimate the line of best fit: $y=m x+b$ where the slope $(m)$ and the y-intercept $(b)$ are given by

$$
m=\frac{n\left(\sum x y\right)-\left(\sum x\right)\left(\sum y\right)}{n\left(\sum x^{2}\right)-\left(\sum x\right)^{2}} \text { and } b=\frac{\sum y-m\left(\sum x\right)}{n}
$$


The first function estimates the rate of neuron decrease in the ten samples of the control group with a CDR of 0 . In this case, the line of best fit has a very small, negligible slope of -0.0013 and we approximate it with a constant function $y=7$ (see Table 1, Figure 1).

The second function estimates the number of neuron decrease for 5 patients suffering mild Alzheimer's disease with CDR=0.5-1. Here we have $m=-0.0261$ and $b=7.2616$ (See Table 2, Figure 2). The third function estimates the rate of neuron decrease in four patients suffering from severe Alzheimer's disease with CDR of 3. Where we use the quadratic equation $y=a x^{2}+b x+c$

After calculating the values of $a, b$, and $c$ using the least squares method through an algorithm build into Microsoft Office, we get $y=-0.0156 x^{2}+2.3018 x-81.793$ (See Table 3 , Figure 3). Besides polynomial type regression of order $2\left(R^{2}=0.90\right)$ we have tried exponential, linear, logarithmic, and power regressions. The values of $R^{2}$ that we have obtained for these regression types are $0.56,0.43,0.41$, and 0.52 respectively. This shows that, among the considered types, the quadratic regression is by far the most reliable.

\section{DISCUSSION}

The obtained equations suggest that the rate of EC neuron decay in the patients without Alzheimer's is close to zero, linear in mild cases, and quadratic in severe cases. However the used dataset was relatively small and so even a few outliers could have significantly affected our predictions. Hence we believe that a larger dataset could have significantly improved the reliability of our findings. 


\section{CONCLUSION AND RECOMMENDATIONS}

Our observations suggest that the patients with Alzheimer's gradually suffer increasingly faster entorhinal cortex (EC) neuron deterioration as the disease progresses while there is an insignificant loss of EC neurons in the entorhinal cortex during normal aging. For our estimates, we have used data generated by neurology service in the Massachusetts general hospital in Boston (Gomez-Isla 4492). However, the data is obtained from postmortem brain samples collected from individuals with and without Alzheimer's disease. Hence a method for estimating the quantity of EC neurons in live patients is a crucial step towards a better technique for diagnosing Alzheimer's. Perhaps integrating optical fractionator and EKG could help solve this problem.

\section{REFERENCES}

"Entorhinal Cortex." 11 April 2012. Scholarpedia. $<$ http://www.scholarpedia.org/article/Entorhinal_cortex>.

Gomez-Isla, Teresa, et al. "Profound Loss of Layer II Entorhinal Cortex Neurons Occurs in Very Mild Alzheimer's Disease." The Jurnal of Neuroscience (1996): 4491-4500.

Hamann, Barbara P. "Disease: Identification, Prevention, and Control." Boston: McGraw Hill (2007): 402--403.

"Prevention and Treatment of Alzheimer's Disease." The Light Party New Political Paradigm and Health Care (2010): 11.

Sear, Who. "Alzheimer's Disease: Mild Memory Loss: An Inevitable Consequence of Ageing." Regional Health Situation, and World AIDS Day, Health Report. (2010).

Sutherland, Greg T., Michal Janitz and Jillian J. Kril. "Understanding The Pathogenesis Of Alzheimer's Disease: Will RNA-Seq Realize The Promise Of Transcriptomics?" Journal Of Neurochemistry 116.6 (2011): 937--946. 


\begin{tabular}{|r|c|c|}
\hline Patient Type & $\begin{array}{c}\text { Average Number } \\
\text { of Neurons }\left(\times \mathbf{1 0}^{\mathbf{6}}\right)\end{array}$ & \begin{tabular}{c} 
Standard Deviation \\
\hline Control
\end{tabular} \\
\hline Mild & 4.912 & 1.14 \\
\hline Severe & 2.23 & 0.52 \\
\hline
\end{tabular}

Table 4: Average neuron number by the patient type

\section{APPENDIX - FIGURES}

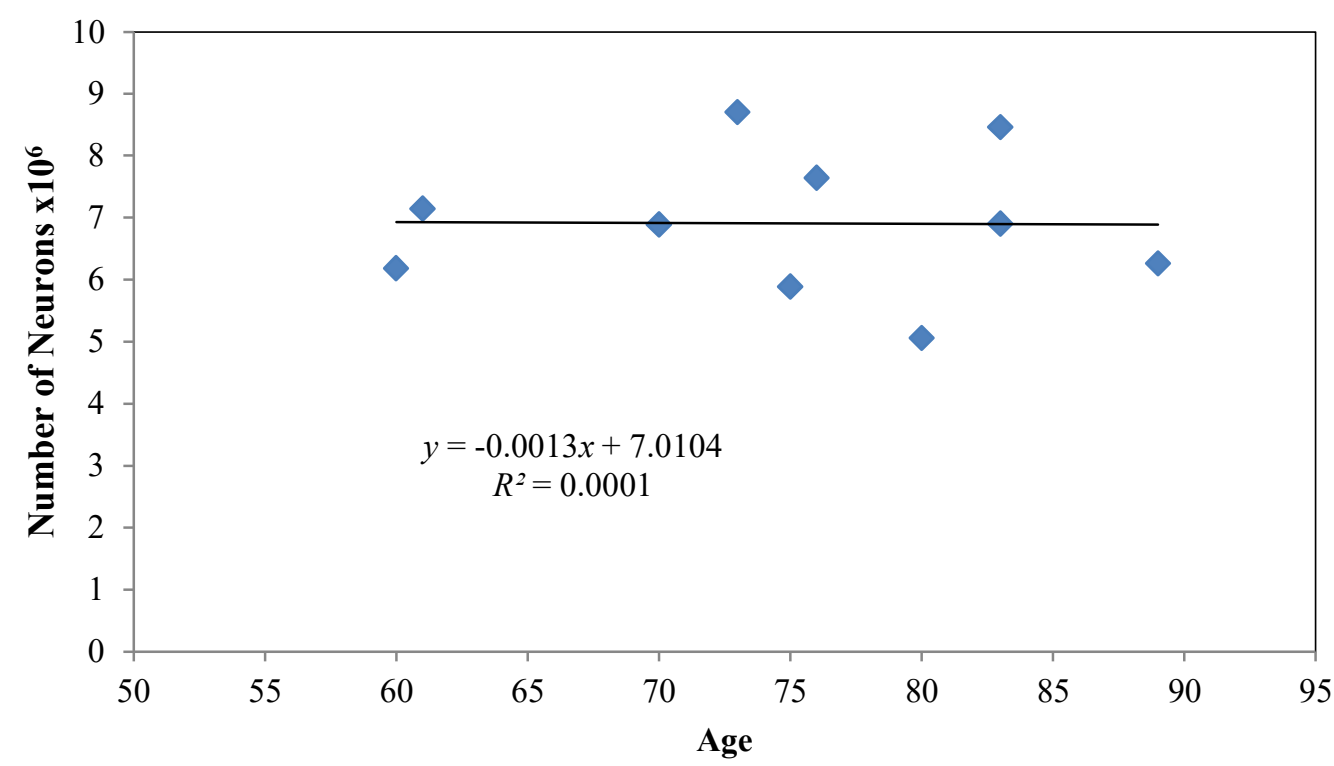

Figure 1: Neuronal counts in entire EC for control subjects

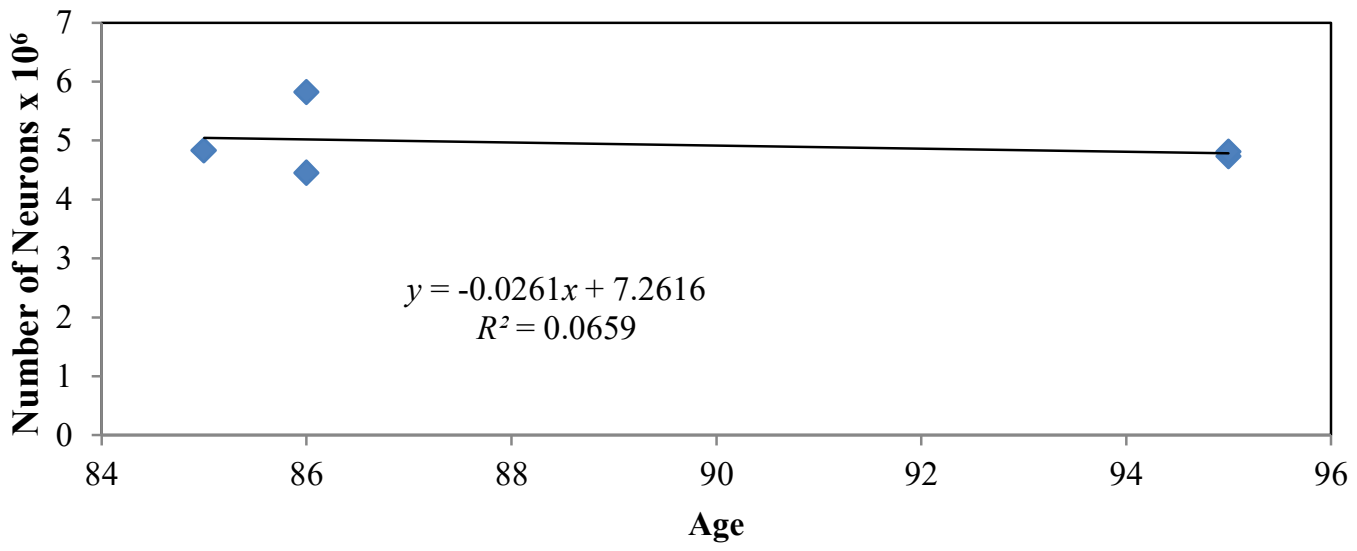

Figure 2: Neuronal counts in the entire EC for mild AD patients 


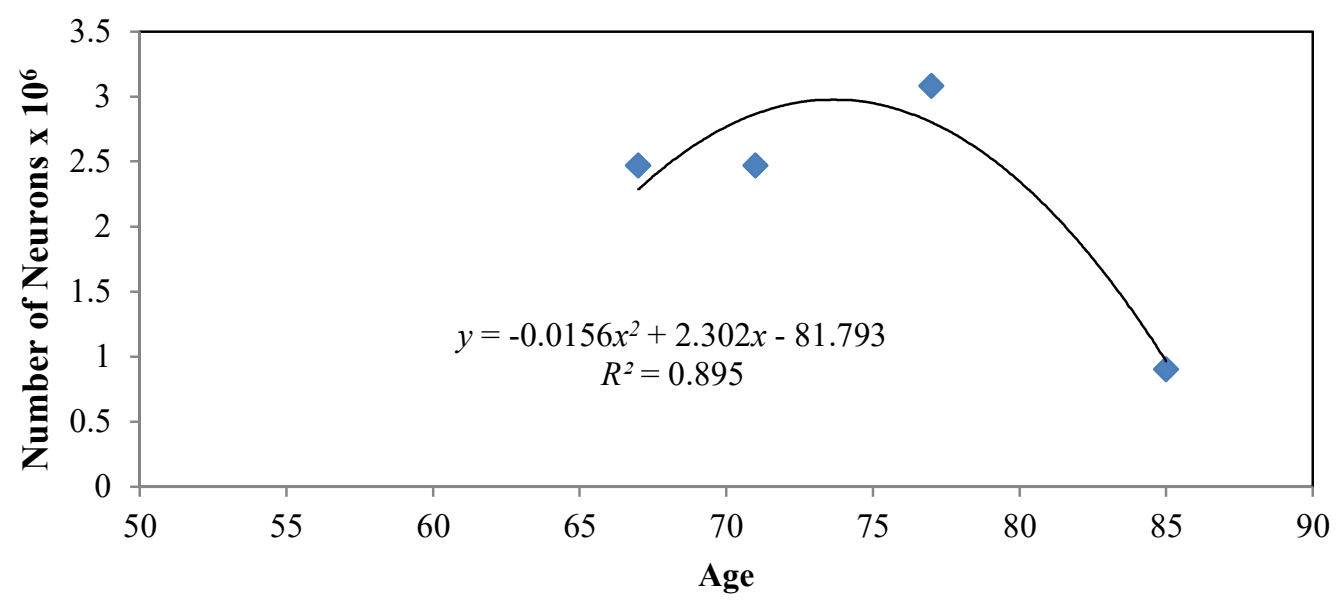

Figure 3: Neuronal Counts in the Entire EC for severe AD Subjects

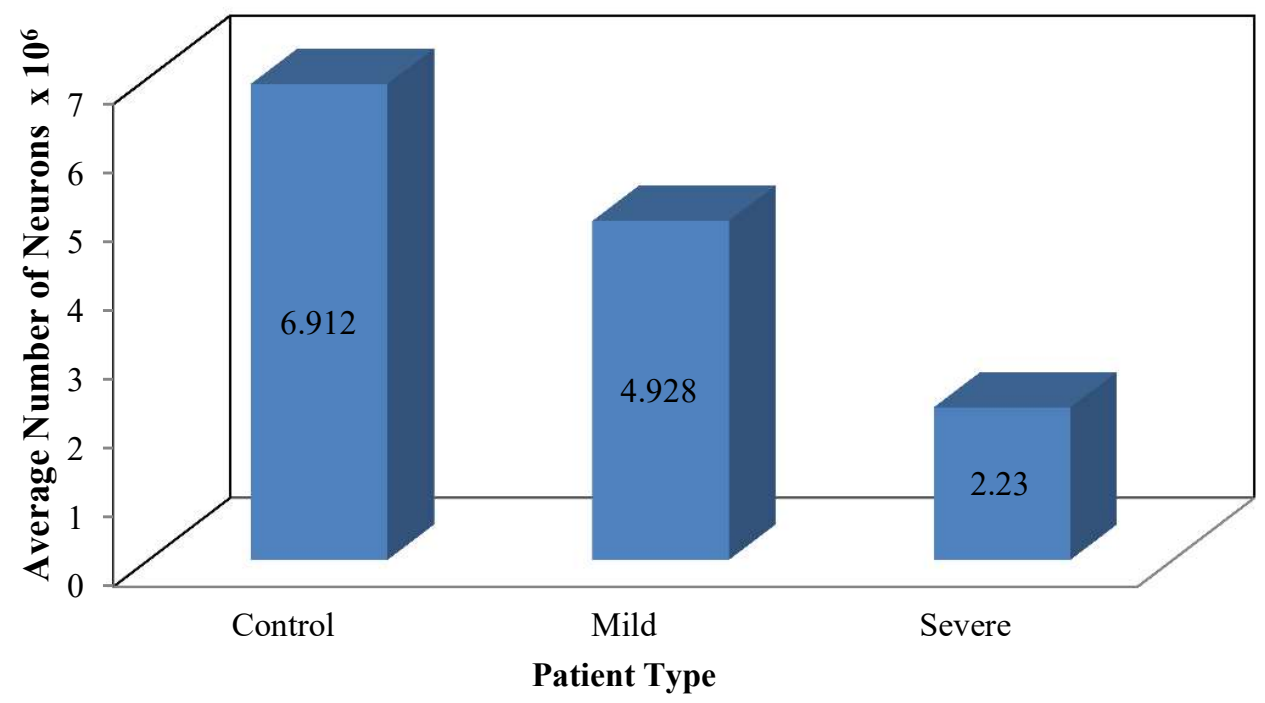

Figure 4: Average Number of Neurons $\left(\times \mathbf{1 0}^{\mathbf{6}}\right)$ 